\title{
Mortality of female gas mask assemblers
}

\author{
B K WIGNALL AND A J FOX \\ From the Department of Radiology, ${ }^{1}$ St George's Hospital, and Department of Mathematics, ${ }^{2}$ The City \\ University, London, $U K$
}

\begin{abstract}
A 30-year follow-up study of the mortality of 500 women employed in manufacturing gas masks during the second world war showed a pronounced excess of deaths from mesothelioma and lung cancer. Although these women were subject only to short periods of exposure, greater excesses were found for those exposed for between one and five years than for those exposed for under one year. Even in the latter group, however, five deaths from lung cancer and four deaths from mesothelioma were recorded compared with 1.5 deaths and 0.1 deaths expected $(p \simeq 0.02)$. An excess of deaths from cancer of the ovary was also found, and this appeared to be related to exposure to asbestos.
\end{abstract}

As part of a study of textile workers exposed predominantly to crocidolite asbestos, Knox et $a l^{1}$ included one of the earliest reports on the mortality of female employees. The number of deaths recorded in their study was twice that expected, and the authors suggested that the health of female asbestos workers should be further investigated. At the same time Newhouse and Thompson ${ }^{2}$ described an investigation into patients in whom a diagnosis of mesothelioma had been made at necropsies. Seventeen women in their series were found to have been occupationally exposed to asbestos, principally crocidolite. The exposure was in general less than six years, and there was a long interval between first exposure and onset of mesothelioma. In 1972 Newhouse et $^{\mathrm{al}} \mathrm{l}^{3}$ reported on a prospective mortality study of women who had manufactured asbestos textiles and insulation materials. This study showed an excess of mortality mainly due to cancers of the lung and pleura, which was most pronounced for women exposed to asbestos for more than two years.

When a Nottingham woman died in 1965 and a postmortem examination showed a pleural mesothelioma, it was suspected that she had been occupationally exposed to asbestos and this prompted a search of the employee files at a local factory where she had worked. The patient was one of about 1600 workers, almost all women, who had, during the second world war, assembled gas masks mainly destined for the armed Forces. In May 1972 Jones $^{4}$ (at a meeting of the British Division of the Inter-

Received 23 January 1981

Accepted 13 May 1981 national Academy of Pathology at Wolverhampton) reported that 10 women who had developed mesothelioma had been doing this work. The number had risen to 26 by 1976.4

These observations on the incidence of mesothelioma at this factory led one of us (BKW) to identify and trace a group of female employees who had worked in a particular part of the plant where military gas masks were made and who, by the nature of their work, were considered likely to have been exposed to higher concentrations of crocidolite asbestos than the remainder of the work force. By means of a follow-up of this group at the National Health Service Central Register using a prospective study design we were able to determine the total mortality experience of the group and to relate the observed patterns to measures of exposure to crocidolite. In a parallel study, Jones et $^{\mathbf{5}} \mathbf{l}^{5}$ reported on the incidence of cancer in the total work population, including all those employed in all stages of the assembly of both civilian and military gas masks.

\section{Methods}

POPULATION STUDIED

Scrutiny of company records showed that between 1939 and 1944 about 1600 employees, almost all women, had assembled gas masks. After 1940, production was mainly of military masks, one of which was obtained and dismantled. It contained filter pads that analysis showed to consist of merino wool mixed with $15 \%$ pure crocidolite asbestos. ${ }^{5}$ The crocidolite proved to be an uncommon variety, a very fine fibre type mined in Western Australia. From 
information provided by retired management, it seemed likely that only those employees who weighed filter pads or who clamped them into holders would have been directly exposed to asbestos dust. Despite the exhaust ventilation of the assembly lines, these women reported that by the end of the working day they were covered in fluff from the pads.

Therefore, for the purpose of this study, only these women plus those working in the same room were selected for tracing and analysis. This group numbered 535 (table 1), only one-third of the group covered by Jones ${ }^{5}$ but nevertheless a sub-group with more precise exposure data.

Table 1 Number of women covered by the study and outcome of trace, 1 January 1978

\begin{tabular}{|c|c|c|}
\hline \multirow[t]{2}{*}{ Outcome of trace } & \multicolumn{2}{|c|}{ Women } \\
\hline & No & $\%$ \\
\hline Total on lists & 535 & 100 \\
\hline Traced & 500 & 93 \\
\hline Alive & 354 & 66 \\
\hline Dead & 138 & 26 \\
\hline Embarked & 8 & 1 \\
\hline Not traced & 35 & 7 \\
\hline Insufficient identification & 18 & 3 \\
\hline Not found at NHSCR & 17 & 3 \\
\hline
\end{tabular}

NHSCR $=$ National Health Service Central Register.

Relevant departmental wage sheets for the years 1939-44 were obtained from the payroll department, and these contained the surname, initials, marital status, and date of birth of each employee, and indicated whether she was employed full-time or part-time. The personnel and industrial health records were used to provide christian names, any change of surname by marriage, and home address as well as dates of joining and leaving the company and dates of transfer between departments. The latter records were incomplete but were used to identify those women who had been employed on the production of military masks.

Identification details for all women were then submitted to the Office of Population Censuses and Surveys' National Health Service Central Register, which reported the vital status of individuals in this group and forwarded coded copies of death certificates for all women who had died. Of the $7 \%$ of women not found in the NHSCR, more than half lacked adequate identification details to enable a proper search to be made. Just over a quarter of the population had died in the period under study.

\section{Exposure}

In general, the wage sheets indicated only the building in which women had worked without referring to the actual work done. Before 1942, however, women who weighed and clamped pads were paid directly by the chief inspector of armaments and were designated "CIA" on the wage sheets. These women constitute our high asbestos exposure subgroup.

Of the other women on these wage sheets, some had been employed on a separate floor and solely on face-piece assembly - for example stitching webbing and fitting eye pieces. Between 1965 and 1970 one of us (BKW) attempted to contact those women still alive to obtain an indication of this work. On the basis of this follow-up, these women were separated for the period 1971 onwards into three subgroups: those who had handled the pads or had worked in the same room (definitely exposed to asbestos), those who had never been so employed (definitely not exposed), and those who were not contacted or who did not remember their exposure.

\section{Duration of employment}

"Duration of employment" is used here to indicate the period spent working on one or other of the processes mentioned above. It excludes periods working in other departments before or after employment on gas mask filter assembly. Table 2 indicates that $35 \%$ of those 384 women for whom employment records were complete were employed for under six months; only $4 \%$ were exposed for over five years. Studies of people exposed for such short periods to high concentrations of asbestos are of particular interest for the light they shed on the latency from exposure to effect.

Table 2 The distribution of women, in particular those paid by the chief inspector of armaments (CIA workers), by duration of employment

\begin{tabular}{lcc}
\hline $\begin{array}{l}\text { Duration of employment } \\
\text { (months) }\end{array}$ & All women & CIA workers \\
\hline$<5$ & 133 & 20 \\
$6-11$ & 70 & 17 \\
$12-17$ & 40 & 8 \\
$18-23$ & 44 & 8 \\
$24-35$ & 54 & 7 \\
$36-47$ & 24 & 2 \\
$48-59$ & 5 & 3 \\
$\geqslant 60$ & 14 & 1 \\
Not known & 116 & - \\
Total No & 500 & 66 \\
\hline
\end{tabular}

\section{Results}

Observed and expected deaths in the period 1951-77 are given in table 3 by cause of death. Overall mortality was a little below expected (SMR 96), but mortality from all cancers (SMR $177 \mathrm{p}<0.01)$ and, in particular, cancer of the lung (SMR $273 p<0.01)$ 
Table 3 Observed and expected deaths 1951-77 by cause

\begin{tabular}{|c|c|c|c|}
\hline \multirow[t]{2}{*}{ Cause of death (ICD range) } & \multicolumn{3}{|l|}{ Deaths } \\
\hline & Observed & Expected & $S M R$ \\
\hline All cancers $(140-209)$ & 64 & $36 \cdot 2$ & 177 \\
\hline Cancer of lung (162) & $10+$ & $3 \cdot 7$ & 273 \\
\hline Cancer of stomach $(151,2,3,4)$ & 7 & $10 \cdot 7$ & 65 \\
\hline Cancer of breast (174) & 7 & $8 \cdot 0$ & 88 \\
\hline Mesothelioma $(158,163)^{*}$ & $12 \ddagger$ & $0 \cdot 2$ & 7500 \\
\hline Cancer of ovary $(183)^{*}$ & 6 & $2 \cdot 8$ & 213 \\
\hline Circulatory diseases $(390-458)$ & 43 & $68 \cdot 9$ & 63 \\
\hline Respiratory diseases $(460-519)$ & 11 & $14 \cdot 6$ & 76 \\
\hline Bronchitis (490-493) & 3 & $4 \cdot 4$ & 68 \\
\hline Asbestosis (515.2) & 1 & - & \\
\hline Accidents and violence (800-999) & 7 & $4 \cdot 7$ & 148 \\
\hline All causes & 13.3 & $139 \cdot 0$ & 96 \\
\hline
\end{tabular}

* One cancer of the ovary was found on histological examination to be a mesothelioma of the peritoneum.

†In addition there was one cancer of larynx in 1977.

¥Includes one intrathoracic carcinoma in 1962 , coded to ICD 163.9 .

and mesothelioma (SMR $7500 \mathrm{p}<0.01$ ) was raised. Mortality from circulatory and respiratory diseases was low.

Table 4 indicates that the excess from lung cancer was greatest in the younger age groups whereas that for mesotheliomas was spread across the age groups. Of the 12 deaths from mesothelioma observed, seven were in women aged over 65.

Table 4 Observed and expected deaths by cause and age

\begin{tabular}{|c|c|c|c|}
\hline \multirow[t]{2}{*}{ Cause of death } & \multicolumn{3}{|l|}{ Age } \\
\hline & $25-54$ & $55-64$ & $65-74$ \\
\hline \multicolumn{4}{|l|}{ All cancers } \\
\hline Observed & $19 * *$ & 18 & $27 * *$ \\
\hline Expected & $9 \cdot 463$ & $12 \cdot 695$ & 13.986 \\
\hline SMR & 201 & 142 & 193 \\
\hline \multicolumn{4}{|l|}{ Lung cancer } \\
\hline Observed & $4^{*}$ & 4 & 2 \\
\hline Expected & $0 \cdot 809$ & 1.481 & $1 \cdot 373$ \\
\hline SMR & 494 & 270 & 146 \\
\hline \multicolumn{4}{|l|}{ Mesothelioma } \\
\hline Observed & $3 * *$ & $2 * *$ & $7^{* *}$ \\
\hline Expected & 0.039 & 0.067 & 0.057 \\
\hline SMR & 7692 & 2985 & 12281 \\
\hline \multicolumn{4}{|l|}{ All causes } \\
\hline Observed & 23 & 37 & 73 \\
\hline Expected & $22 \cdot 623$ & $35 \cdot 208$ & $81 \cdot 201$ \\
\hline SMR & 102 & 105 & 90 \\
\hline
\end{tabular}

${ }^{*} \mathrm{p}<0.05, \quad{ }^{* *} \mathrm{p}<0.01$

As might be expected from other studies of industrial cohorts ${ }^{6}$, mortality in the early period of follow-up was low (table 5). Although from this table the pronounced excess from mesothelioma appears to have come in the 1960 s while that from lung cancer was observed only in the 1970s, table 6 indicates that this simply reflects the small number of cases. Table 5 also suggests an excess of other cancers that may be found in the late 1970 s.
Table 5 Observed and expected deaths by cause and period of study

\begin{tabular}{|c|c|c|c|}
\hline \multirow[t]{2}{*}{ Cause of death } & \multicolumn{3}{|c|}{ Period of study } \\
\hline & $1951-60$ & $1961-70$ & $1971-77$ \\
\hline \multicolumn{4}{|l|}{ All causes } \\
\hline Observed & $12 * *$ & 56 & 65 \\
\hline Expected & 26.05 & 53.65 & $59 \cdot 34$ \\
\hline SMR & & 104 & 110 \\
\hline \multicolumn{4}{|l|}{ All cancers } \\
\hline Observed & 5 & $27^{* *}$ & $32 * *$ \\
\hline Expected & 8.09 & $14 \cdot 45$ & 13.61 \\
\hline SMR & 62 & 187 & 235 \\
\hline \multicolumn{4}{|l|}{ Lung cancer } \\
\hline Observed & - & 3 & $7 * *$ \\
\hline Expected & 0.54 & $1 \cdot 43$ & 1.69 \\
\hline SMR & - & 209 & 414 \\
\hline \multicolumn{4}{|l|}{ Mesothelioma } \\
\hline Observed & - & $6^{* *}$ & $6^{* *}$ \\
\hline Expected & 0.03 & 0.07 & 0.06 \\
\hline SMR & - & 8775 & 10107 \\
\hline \multicolumn{4}{|l|}{ Other cancers $†$} \\
\hline Observed & 5 & 18 & 19 \\
\hline Expected & $7 \cdot 52$ & 12.95 & $11 \cdot 86$ \\
\hline SMR & 66 & 139 & 152 \\
\hline
\end{tabular}

$* * \mathrm{p}<0.01$

tOne cancer of the ovary in 1967 was found on histological examination to be a mesothelioma of the peritoneum.

Table 6 Deaths from cancer of the lung and mesothelioma by year of death

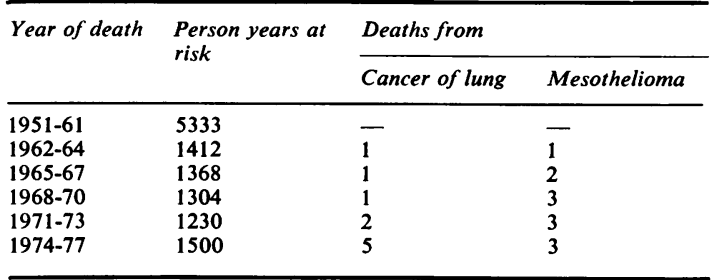

In table 7 deaths are separated according to exposure to asbestos. Mortality for the CIA workers, those definitely exposed to asbestos from the early 1940s, was higher than for the other groups. The overall SMR for the group was $208(\mathrm{p}<0.01)$ and comprised SMRs of 625 for lung cancer ( $p>0.05$ ), 15000 for mesothelioma $(p<0.01)$, and 1481 for cancer of the ovary $(p<0.01)$. The group with the next highest mortality was those women who, although not CIA workers, were confirmed as exposed to asbestos. Although their overall SMR was only 112 , these women recorded pronounced excesses of cancer of the lung and mesothelioma. It should also be noted from the table that five deaths from cancer of the ovary were found among women definitely exposed to asbestos ( 0.63 expected), whereas none was found among those definitely not exposed $(0.40$ expected $)$.

Table 8 describes an attempt to relate mortality to duration of employment. Clear relationships of higher SMRs are seen for overall mortality and for 
Table 7 Observed and expected deaths by cause and exposure to asbestos

\begin{tabular}{|c|c|c|c|c|c|c|c|c|c|c|c|c|c|c|c|}
\hline \multirow[t]{3}{*}{ Cause of death } & \multicolumn{15}{|c|}{ Exposure to asbestos } \\
\hline & \multicolumn{3}{|c|}{$C I A+1951-77$} & \multicolumn{3}{|c|}{ Not CIA $¥ 1951-70$} & \multicolumn{3}{|c|}{ Asbestos $\ddagger 1971-7$} & \multicolumn{3}{|c|}{ Not asbestos $\ddagger 1971-7$} & \multicolumn{3}{|c|}{$\begin{array}{l}\text { Asbestos not known } \\
1971-7\end{array}$} \\
\hline & $O b s$ & Exp & $S M R$ & Obs & Exp & $S M R$ & Obs & Exp & $S M R$ & $O b s$ & Exp & $S M R$ & Obs & $\operatorname{Exp}$ & $S M R$ \\
\hline All cancers & $15^{* *}$ & $3 \cdot 04$ & 493 & 23 & $20 \cdot 79$ & 111 & 17 & $5 \cdot 31$ & 320 & 7 & $5 \cdot 77$ & 121 & 2 & $1 \cdot 24$ & 161 \\
\hline Lung & 2 & 0.32 & 625 & 3 & $1 \cdot 82$ & 165 & $5 * *$ & 0.64 & 781 & - & 0.72 & - & - & $0 \cdot 16$ & - \\
\hline Mesothelioma* & $3^{* *}$ & 0.02 & 15000 & 4 & 0.09 & 4444 & $5 * *$ & 0.02 & 22261 & - & 0.03 & - & - & 0.01 & - \\
\hline Ovary* & $4 * *$ & 0.27 & 1481 & 1 & $1 \cdot 70$ & 59 & 1 & 0.36 & 278 & - & 0.40 & - & - & 0.09 & - \\
\hline All causes & $18^{* *}$ & $8 \cdot 66$ & 208 & 58 & $75 \cdot 14$ & 77 & 28 & $25 \cdot 08$ & 112 & 27 & $25 \cdot 04$ & 108 & 2 & $5 \cdot 12$ & 39 \\
\hline
\end{tabular}

* One cancer of the ovary in the CIA group was found on histological examination to be a mesothelioma of the peritoneum.

$*$ p $<0.01$.

+ClA workers were paid by the chief inspector of armaments and were heavily exposed to asbestos.

¥Women on lists were initially classified as "CIA" and "not CIA." In 1965-70 an attempt was made to trace women and to discover whether or not the jobs performed implied that they had been exposed to asbestos. Therefore from 1971 onwards the "not CIA" could be separated according to asbestos exposure into (a) known asbestos exposure, (b) known not exposed, and (c) not known whether or not exposed.

Table 8 Mortality of women employed for under five years who were alive six years after entry to the industry by duration of employment

\begin{tabular}{|c|c|c|c|c|c|}
\hline \multirow[t]{2}{*}{ Cause of death } & \multicolumn{5}{|c|}{ Duration of employment } \\
\hline & $<1$ yea & 1 year & 2 years & 3 years & 4 years \\
\hline \multicolumn{6}{|l|}{ All causes } \\
\hline Observed & 52 & 27 & 17 & 8 & 2 \\
\hline Expected & $55 \cdot 34$ & $26 \cdot 19$ & $14 \cdot 68$ & $6 \cdot 54$ & 0.62 \\
\hline SMR & 94 & 103 & 116 & 122 & 323 \\
\hline \multicolumn{6}{|l|}{ All cancers } \\
\hline Observed & 24 & 15 & 7 & 7 & 2 \\
\hline Expected & 14.49 & 6.52 & 3.90 & 1.42 & 0.23 \\
\hline SMR & 166 & 230 & 179 & 493 & 870 \\
\hline \multicolumn{6}{|l|}{ Lung cancers } \\
\hline Observed & 5 & 2 & 1 & 1 & - \\
\hline Expected & $1 \cdot 47$ & & $1 \cdot 19$ & & \\
\hline \multicolumn{6}{|l|}{ Mesotheliomas* } \\
\hline Observed & 4 & 3 & 1 & 3 & 1 \\
\hline \multicolumn{6}{|l|}{ Ovarian cancers* } \\
\hline Observed & 2 & 2 & - & 1 & - \\
\hline Expected & $1 \cdot 13$ & & 0.95 & & \\
\hline
\end{tabular}

*One cancer of the ovary in the one year employment group was found on histological examination to be a mesothelioma of the peritoneum.

cancers in particular. Once the deaths are separated into more specific causes, however, the numbers expected are too few for stable estimates of the SMRs to be obtained.

Nevertheless, for both mesothelioma and cancer of the ovary mortality would appear to be higher in women exposed for one year or more than in women exposed for less than one year. The same pattern with duration of exposure is found for the CIA workers, although this is now based on even fewer deaths (table 9). The table is interesting because the SMRs even for those exposed for less than one year are considerably higher than those shown in table 8.
Table 9 Mortality of CIA workers who were employed for less than five years who were alive six years after entry to the industry by duration of employment

\begin{tabular}{|c|c|c|c|c|c|c|}
\hline \multirow[t]{3}{*}{ Cause of death } & \multicolumn{6}{|c|}{ Duration of employment } \\
\hline & \multicolumn{3}{|c|}{ Less than one year } & \multicolumn{3}{|c|}{ One year to four years } \\
\hline & Obs & Exp & $S M R$ & $O b s$ & Exp & $S M R$ \\
\hline All causes & 7 & $4 \cdot 95$ & 141 & $11 * *$ & $3 \cdot 63$ & 303 \\
\hline All cancers & $7 * *$ & $1 \cdot 71$ & 409 & $8^{* *}$ & $1 \cdot 12$ & 714 \\
\hline Lung cancer & $2^{*}$ & $0 \cdot 19$ & 1053 & - & 0.14 & - \\
\hline Mesothelioma & $\overline{1}$ & 0.00 & $x$ & 2 & 0.00 & $\infty$ \\
\hline
\end{tabular}

* $\mathrm{p}<0.05 ; * * \mathrm{p}<0.01$.

tIn addition one cancer of the ovary in the one to four year exposures group was found on histological examination to be a mesothelioma of the peritoneum.

Table 10 points to a difference in mortality between those women who left the firm in 1942 or 1943 and those who left in 1944; the former group,

Table 10 Mortality of women employed for less than five years who were alive six years after entry to the industry by duration of employment and year of leaving the company

\begin{tabular}{|c|c|c|c|c|c|c|}
\hline \multirow{3}{*}{$\begin{array}{l}\text { Year of leaving } \\
\text { company }\end{array}$} & \multicolumn{6}{|c|}{ Duration of employment } \\
\hline & \multicolumn{3}{|c|}{ Less than one year } & \multicolumn{3}{|c|}{ One year to four years } \\
\hline & $O b s$ & Exp & $S M R$ & Obs & $\operatorname{Exp}$ & $S M R$ \\
\hline \multicolumn{7}{|l|}{1942 or 1943} \\
\hline All causes & 23 & $21 \cdot 90$ & 105 & 22 & $18 \cdot 12$ & 121 \\
\hline All cancers & $13^{*}$ & $6 \cdot 34$ & 205 & 10 & $5 \cdot 19$ & 193 \\
\hline Lung cancer & 3 & 0.66 & 455 & $3^{*}$ & 0.53 & 566 \\
\hline Mesothelioma $\dot{ }$ & $1^{*}$ & 0.02 & 5000 & $1 *$ & 0.02 & 5000 \\
\hline \multicolumn{7}{|l|}{1944} \\
\hline All causes & 25 & $29 \cdot 16$ & 86 & 27 & $28 \cdot 00$ & 96 \\
\hline All cancers & 7 & $6 \cdot 71$ & 104 & $17^{* *}$ & $6 \cdot 64$ & 256 \\
\hline Lung cancer & 1 & $0 \cdot 65$ & 154 & 1 & 0.64 & 156 \\
\hline Mesothelioma & $2 * *$ & 0.03 & 6667 & $6 * *$ & 0.03 & 20000 \\
\hline
\end{tabular}

$* p<0.05 ; * * p<0.01$.

+ In addition, one cancer of the ovary in the one to four year exposures group was found on histological examination to be a mesothelioma of the peritoneum. 
who would not have been exposed in 1944, were found to have higher rates of lung cancer but the latter group, particularly those exposed for more than a year, were found to have very high rates of mesothelioma.

\section{Discussion and conclusions}

While it might have been expected that this study would confirm numerous previous observations of a relation between exposure to asbestos and mortality it is of particular interest because it looks at the mortality of women (who have smoked less than men) and because it relates that mortality to exposures of very short duration. In studies of male asbestos workers exposed to crocidolite the deaths from lung cancer generally far outnumber deaths from mesothelioma. In the present study similar numbers of deaths were observed from both causes. Since mortality from both causes was clearly related to the category of exposure and there was the suggestion that it was also related to duration of employment, it is highly unlikely that these findings might be explained by exposures other than to asbestos.

The excess of deaths from carcinoma of the ovary was unexpected at the start of the study but appears to be related directly to exposure to asbestos.

To check whether any of these women had in fact died from mesothelioma of the peritoneum we contacted Dr Jones, a pathologist who had obtained histological material for many of the deaths to women in this work force. ${ }^{46}$ Of the six cases, one was found to have been reclassified as a mesothelioma of the peritoneum but two were confirmed as cancer of the ovary. No histological material was found for the other three cases. At this stage, therefore, we have assumed that the diagnosis on the death certificate for these cases was accurate but would not rule out the possibility that one or more of these cases may also have been a mesothelioma. It would be of interest consequently to find whether other studies of female asbestos workers also point to raised mortality from cancer of the ovary.

AJF became concerned in the project while at the Office of Population, Censuses, and Surveys, who covered the cost of tracing the 535 women at the NHSCR. The study could not have been completed without the work of NHSCR research staff and the support staff of the medical statistics division of OPCS.

Requests for reprints should be sent to AJF.

\section{References}

${ }^{1} \mathrm{Knox}$ JF, Doll RS, Hill ID. Cohort analysis of changes in incidence of bronchial carcinoma in a textile asbestos factory. New York Academy of Sciences 1965;132:526-35.

${ }^{2}$ Newhouse ML, Thompson H. Epidemiology of mesothelial tumours in the London area. New York Academy of Sciences 1965;132:579-88.

${ }^{3}$ Newhouse ML, Berry G, Wagner JC, Turok ME. A study of the mortality of female asbestos workers. $\mathrm{Br} J$ Ind Med 1972;29:134-41.

${ }^{4}$ Jones JSP, Pooley FD, Smith PG. Factory populations exposed to crocidolite asbestos-a continuing survey. INSERM 1976;52:117-20.

${ }^{5}$ Jones JSP, Smith PG, Pooley FD, et al. The consequences of exposure to asbestos dust in a wartime gas-mask factory. Proceedings of the 1979 Lyons Conference on The Biological Effects of Mineral Fibres. Lyons: International Agency for Research in Cancer, 1981.

${ }^{6}$ Fox AJ, Collier PF. Low mortality rates in industrial cohort studies due to selection for work and survival in the industry. Br J Prev Soc Med 1976;30:225-30. 